\title{
A New Role for the Military: Preventing Enemies from Arising-Reviving an Ancient Approach to Peace
}

\author{
David R. Leffler \\ Executive Director, \\ Center for Advanced Military Science (CAMS), \\ USA
}

\begin{abstract}
The military's primary job is to fully protect its country from attack by enemies, both foreign and domestic. In many countries, lives are lost and vast resources are expended in defenses against these enemies. Preventing enemies from arising would be both effective and cost effective in establishing peace. This paper introduces a new role for the military: "Prevention Wings" whose purpose is to prevent enemies from arising. A new approach derived from the ancient Vedic tradition and termed "Invincible Defense Technology (IDT)," is supported by over 50 scientific studies indicating it can achieve this goal as well as assist in peacemaking, peacekeeping, and peacebuilding roles. Two to three percent of a nation's military personnel would be trained on a voluntary basis in the primary components of IDT-the techniques known as the Transcendental Meditation ${ }^{\circledR}(\mathrm{TM} \circledast)$ ) and TM-Sidhi ${ }^{\circledR}$ programs. ${ }^{1}$ Peerreviewed studies show that IDT reduces the collective societal stress held by many to be responsible for war, terrorism, and crime. The absence of collective stress translates into the absence of tension between the countries, religious groups, or even within individual terrorists. By applying this human resource-based, non-lethal, and non-destructive technology, it is proposed that any military can reduce societal stress and prevent enemies from arising.
\end{abstract}

Keywords : Militray, inviacible defense technology, Transcendental meditation

\section{SOCIAL STRESS AND THE CYCLE OF WAR}

As illustrated in Figure 1, war is a cycle. Social stress builds, and diplomats cannot solve their differences. Groups take sides, resulting in enemies. Military strength is meant to deter enemies. When deterrence fails, militaries are called in to fight. This seems to solve the problem, but stress remains, fueling future wars.

* The material presented by the author does not necessarily portray the viewpoint of the editors and the management of the Institute of Business \& Technology (BIZTEK) or Executive Director, Center for Advanced Military Science (CAMS).

*David R. Leffler : dr@invinciblemilitary.org

C JMSS is published by the Institute of Business and Technology (BIZTEK).

Main Ibrahim Hydri Road, Korangi Creek, Karachi-75190, Pakistan. 
Figure 1.

The Military Fails to Address Social Stress

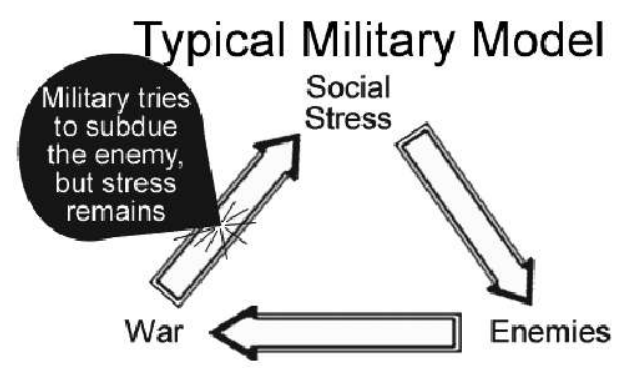

War and Terrorism Continue

Even countries that have a strong military can still suffer from terrorism and war, and casualties. If their militaries were both strong and invincible, war, terrorism and casualties would end. In this context, a military becomes invincible when it has no enemies. No enemies means, no war and no terrorism.

The author proposes that each country in the world create a Prevention Wing of the Military ${ }^{\mathrm{SM}} 1$ consisting of a specific number of individuals trained in proven techniques of social stress abatement, specifically, the Transcendental Meditation and TM-Sidhi programs. In this Invincible Military Model (Figure 2), the military addresses collective social stress to prevent or pacify enemies. The war cycle is broken.

Figure 2.

The Military Uses IDT to Break the War Cycle

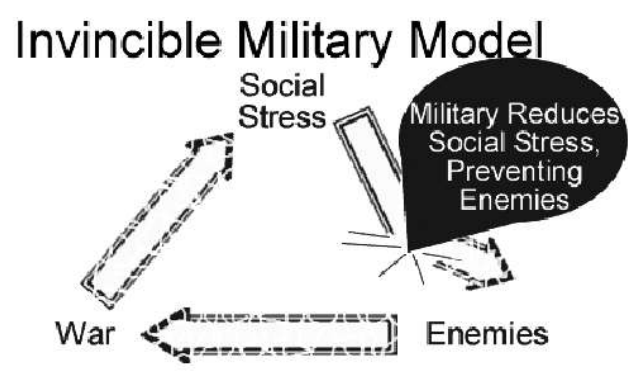

The Military Breaks the War Cycle

Acknowledging its systematic, repeatable nature, the methodology is called Invincible Defense Technology (IDT). This technology implies a theoretical explanation from the domain of consciousness as a field. Thus, the practice of specific psychophysiological techniques by a group of individuals can be shown to produce a calming influence on the population surrounding the group.

The Transcendental Meditation (TM) program is non-religious and requires no changes in beliefs. It comes from the ancient Vedic tradition of India. The late Maharishi Mahesh Yogi brought out the Transcendental Meditation technique in 1956. Scientists call the increased societal coherence that results from the TM and more advanced TM-Sidhi ${ }^{\circledR}$ programs "the Maharishi Effect." Maharishi predicted that if $1 \%$ of a population practiced the TM program, peace and harmony would increase throughout society. Additionally, he anticipated the same result if the square root of $1 \%$ of a population practiced TM-Sidhi 
program in groups twice daily. These predicted results have been seen repeatedly in published, peer-reviewed scientific research.

\section{SOCIAL RESEARCH ON INVINCIBLE DEFENSE TECHNOLOGY}

More than 50 scientific studies validate the social stress-reducing benefits of IDT. Studies on the Maharishi Effect have been published in leading peer-reviewed journals, such as The Journal of Conflict Resolution, Social Indicators Research, Journal of Crime and Justice, Journal of Mind and Behavior and International Journal of Neuroscience. Most of this research is reviewed in a paper co-written by the author, published by the Security and Political Risk Analysis (SAPRA) think tank, called "An Alternative to Military Violence and Fear-Based Deterrence: Twenty Years of Research on the Maharishi Effect ( Leffler and Walton, 1999).

Scientific studies have found that social indicators, such as acts of terrorism, war deaths, war injuries, conflict levels, and crime rates, showed improvement when enough people practiced these unique psychophysiological techniques. The results include increased progress towards peaceful resolution, and decreases in: war deaths, war injuries, war intensity, property damage, hostile acts, international conflict, and terrorist induced casualties.

An outstanding demonstration of the reduction of social stress through IDT in the United States was documented in Social Indicators Research (Hagelin et al 1999). This intervention took place in the US capital, Washington, DC. Predictions were lodged in advance with government leaders and newspapers. Time series analysis was employed in the study. The research protocol approved by an independent Project Review Board set the experimental period from June 7 to July 30, 1993. The main result was that crime dropped 23\% below the predicted level when the TM-Sidhi group reached its maximum ( $\mathrm{p}<2 \times 10-9$ for weekly data). Weekend effects, temperature, and previous trends in the data did not account for changes. This level of $p$ value is rarely seen in social science research.

During the 1983 Lebanon conflict, when the size of a group of IDT experts in nearby Jerusalem varied, war-related fatalities in Lebanon varied correspondingly from day to day. At the point of highest IDT participant numbers, war deaths dropped by $76 \%$ as participants approached the theoretically desired square root of $1 \%$ of the population.

During the peak of the Lebanon war, replication over two years in seven consecutive experiments gave these results:

- war-related fatalities decreased by $71 \%(\mathrm{p}<10-10)$

- war-related injuries fell by $68 \%(\mathrm{p}<10-6)$

- the level of conflict dropped by $48 \%(\mathrm{p}<10-8)$

- cooperation among antagonists increased by $66 \%(\mathrm{p}<10-6)$.

The likelihood that these combined results were due to chance is less than one part in 1019 , making this effect of reducing societal stress and conflict the most rigorously established phenomenon in the history of the social sciences (Davies \& Alexander 2005).

Maintenance of the effects of IDT is contingent on maintaining the required number of participants. Figure 3 illustrates the effects of changing the number of participants. This chart shows associated changes in the quality of life in Israel during the Lebanon conflict in 1983. Notice the association incorporates a "lag" of one to several days, as well as an "averaging" effect that moderates the impact of changing numbers of participants. Note that the " 0 " point on the $y$-axis represents the threshold number of participants for this population (158 participants). 
Figure 3 .

TM Group Size Vs. Quality of Life in Israel

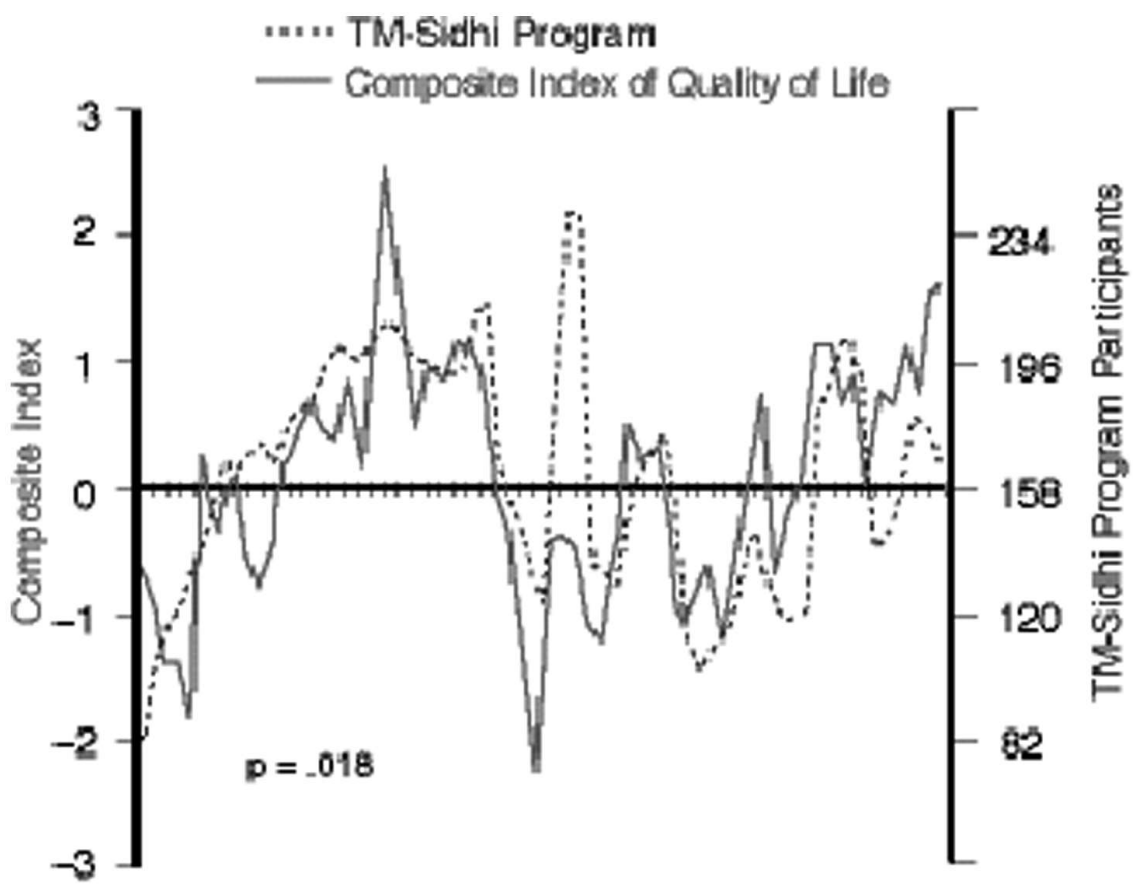

This figure illustrates a highly statistically significant correlation between the number of participants in an IDT assembly and a composite index measuring progress toward peace and quality-of-life in Israel during August and September of 1983. When the number of participants rose, the intensity of the war in Lebanon decreased $\left(\mathrm{p}<10^{-7}\right)$.

Dr. John Hagelin is a Harvard trained physicist who conducted some of the research on IDT. He is the Director of the Institute of Science, Technology, and Public Policy (ISTPP). Dr. Hagelin speaks in detail about the physics of IDT in an online video (Invincible Defense 2007)

A landmark study published in the Journal of Offender Rehabilitation showed a $72 \%$ reduction in deaths due to international terrorism $(p<.025)$ when the global threshold of people practicing the TM-Sidhi program was reached (Orme, Dillbeck and Alexander 2003). These assemblies were held during the years 1983-1985. This study investigated the effects of three large assemblies approaching the Maharishi Effect threshold for the world at that time $(7,000)$. The study, which used data provided by the Rand Corporation, also revealed that international conflict decreased $32 \%(\mathrm{p}<.025)$.

\section{A PROPOSED CAUSAL MECHANISM FOR INVINCIBLE DEFENSE TECHNOLOGY}

IDT's causal mechanism is not completely understood. An explanation of the causality of IDT in biological terms was proposed in a 2005 study in the Journal of Social Behavior and Personality (Walton et al 2005). Serotonin, a powerful neurotransmitter, has been 
shown to produce feelings of happiness, contentment, and even euphoria. Research indicates that low levels of serotonin correlate with aggression, poor emotional moods and violence. The study indicated that when the size of a group of IDT experts changed, serotonin production of people in the nearby community changed correspondingly. Since results were statistically significant, this study offers a plausible neurophysiologic mechanism that may explain reduced aggression and hostility in a whole society. An increase in serotonin activity and a decrease in cortisol appear to be associated with the experience of transcendental consciousness in the advanced individual TM practitioner. During the practice of TM, practitioners experience transcendental consciousness, a proposed fourth state of consciousness with brain activity distinctly different from waking, sleeping and dreaming (Alexander et al 1987). The state of transcendental consciousness produces coherence in the brain, and scientists speculate that this enlivens coherence within the unified field. Apparently, the effect is amplified through group practice. Theoretical physicists allude to the unified field as the basis of all laws of nature. IDT appears to work from this fundamental level. Therefore, through the unified field, there is increased coherence in the non-TM practitioner's brain as well. This increased coherence materially involved serotonin.

Dr. Roger Nelson at Princeton University has found that IDT appears to have a highly significant impact on the Global Consciousness Project (GCP) network of about 65 random number-generating devices situated around the world (Noosphere Princeton 2005). It uses a purely objective measure that differs from any of other sociological and physiological research on IDT.

Moreover, the effect is greater with greater numbers of IDT participants. This is a replication of what Dr. Nelson observed for an applied application of IDT in 2001 a short time after the terrorist attacks on US targets on 11 September 2001. Also, the effect is in the opposite and compensatory direction of the effect of the 11 September 2001 terrorist attacks and other catastrophic events. It seems the random generators become less random during practice of IDT.

\section{ACKNOWLEDGING SKEPTICISM OF IDT}

The shifts in perspective required for scientists to accommodate Einstein's theory of relativity and Plank's quantum principle were not small, but because they were backed by hard evidence, they came to be accepted. A similar situation may exist regarding IDT. The challenge is to maintain perspective. This paper offers a new solution based on research into the powerful influences of group consciousness, a field new to many researchers that has surprising results-results backed by hard evidence.

Just as physics had to undergo a major change in point-of-view and methods of analysis with the introduction of Einstein's theory of relativity, likewise, this paper challenges the reader to accept a similarly large change in methods of social stress abatement to prevent and end terrorism and war. Einstein's theory of relativity indicates that analyses of largescale cosmogenic phenomena must treat gravity as a "field of force" that has an effect on the very shape of space. The equations governing this point of view have been shown to solve important problems in astrophysics that otherwise would continue to remain anomalies and curiosities that defy the classical equations set forth by Sir Isaac Newton.

Likewise, at the other end of the field of scientific measurement, experiment shows that the behavior of subatomic particles fails any description using the equations of classical physics. Explanation of those anomalies using Planck's quantum principle and Heisenberg's uncertainty principle provide the descriptions and manipulations of a whole new world of quantum physics.

The purpose of the above point is to make the case that major steps of progress must 
overcome prejudices. Relativity and quantum mechanics arose from clear evidence. However, the struggle for acceptance of these now-routine equations occurred in the minds of people. We appear to be facing a similar cross-road regarding the nature of "fighting for peace." Proposing a Prevention Wing of the Military is based on strong scientific evidence. However, the struggle for acceptance of the proposed solution remains in the minds of people.

For her doctoral dissertation, Carla Linton Brown at Harvard University interviewed elite policy makers who worked in diplomacy and related fields. She studied how policy makers examined the research into the sociological effects of IDT on quality of life and on reduction of violence and war deaths. She found that when policy makers explored this research, they needed:

- Context in order to evaluate this innovation

- Time away from the daily pressures of responsibility to explore the research and innovation

- Perspective and support from others who may have implemented the program and who could answer practical questions, and

- Cultural acclimation-a way to look beyond stereotypes they may have associated with this innovation.

Some of Dr. Brown's respondents were very receptive to the research, but still had questions about how it worked. For example, diplomats explained to Dr. Brown that although they found the research to be compelling, they were too busy plugging up the latest hole in the Middle East peace process to have the time to consider how this innovation could be used or how it would work.

Dr. Brown also found that many policy makers had stereotypical or prejudicial views about an innovation originating in ancient India. Because of the potential for deliberate misrepresentation of the IDT research by biased reviewers, it is hoped that readers of this paper unfamiliar with IDT research will take the time to carefully study a paper by Dr. Carla Linton Brown that is based on her Harvard University doctoral dissertation. Dr. Brown's research was published in the Journal of Social Behavior and Personality. The Harvard dissertation is available online ${ }^{2}$.

\section{HOW THE TM TECHNIQUE COMPARES TO OTHER TYPES OF MEDITATION}

IDT utilized the Transcendental Meditation and TM-Sidhi programs, which are the most scientifically researched forms of meditations. Different forms of meditation use different methods, and logically get different results ${ }^{3}$. Brain patterns have been scientifically studied to demonstrate different physiological processes during various forms of meditations. Meta-analyses have shown that TM produces uniquely beneficial effects. The various forms of meditation do not produce the same effects, based on comparative research. Meta-analysis comparing the effects of the TM technique, Mindfulness, Zen, Progressive Muscle Relaxation, Tibetan Buddhist and Vipassana meditations, and Benson's Relaxation Response has been conducted. They considered levels of rest, brainwave patterns, and mind-body benefits.

Some other forms of meditation have been found to produce good effects in specific areas. However, EEG and neural imaging studies show that the TM technique creates a unique brain pattern. TM is the only meditation technique demonstrated to create brainwave coherence throughout the brain. The research shows that the TM technique is effective at reducing depression and anxiety, and increasing self-actualization. Deeper rest is obtained through the TM technique than other practices ${ }^{4}$. 
According to Dr. David Orme-Johnson, a Maharishi Effect researcher, "a new study of 60 male subjects in their 40's and 50's found that ultraweak photon emissions were significantly lower at all 12 anatomical locations studied in subjects practicing the Transcendental Meditation technique (TM) and Other Meditation Techniques (OMT= Tao, Zen, Christian, and Hindu Yoga meditations) than in non-meditating controls" ${ }^{5}$ (Van, Ludtke and Van 2008).

\section{PORTABILITY AND PROXIMITY}

IDT need not be employed in exact proximity of conflict or potential conflict. However, best results occur when the system is deployed within local political boundaries of the prejudiced area(s). Simultaneously, deployment of systems within more inclusive boundaries (e.g., regional or country-wide) also creates positive effects across the larger boundaries.

IDT achieves best operating characteristics when all participants comprise one group within close association of each other (proximity averaging 1.5 meters between participants). However, positive effects will still be attained when participants operate in several smaller groups.

Throughout the world, IDT can be land-based or sea-based. Land-based Prevention Wings have been field-tested by militaries. ${ }^{6,7}$ IDT practitioners must be transported to the location (or within proximity of the location) and maintained in a secure facility. Sea-based Prevention Wings are theoretically possible. For instance, the US carrier Kitty Hawk (CV63) supported 1,000 Special Operations Forces onboard for its mission in Afghanistan (Swan \& Horres 2008). Therefore, carrier battle groups supporting IDT experts could be deployed to the Persian Gulf to reduce tensions in the Middle East (Approximate population $=800$ million; $1 \%$ of population $=8$ million; square root of 8 million $=2829$ IDT experts needed to achieve the Maharishi Effect).

\section{ADDITIONAL BENEFITS}

Research allows the prediction of additional benefits of a Prevention Wing of the Military. These benefits include improved governmental cooperation, improved economic trends, decreased crime, improved health conditions, and improved quality of life.

Brazilian warriors learned IDT as part of their military training. A number of Brazilian state governments introduced the technology. More than twenty-six thousand military police officers of all ranks were instructed. ${ }^{8}$ Brazilian scientists documented significant improvements in health and discipline by military police officers and cadets in the State of Bahia, Brazil and the Military Police Academy of Piaui, Brazil, who likewise experienced significant improvements using IDT. ${ }^{9}$

People who learn IDT personally gain from the practice. Extensive research documents benefits to individuals, such as reduced response to stress, less anti-social behavior, reduced domestic violence, and increased hand-eye coordination. Research also reports reductions in post-traumatic stress disorder, doctor visits, alcohol problems, emotional numbness, insomnia, anxiety, family problems, and depression. Holistic growth has been indicated by psycho-physiological means such as increases in global EEG coherence, and through psychological tests of intelligence, moral reasoning, and personality.

IDT provides a solution that promises to reduce deaths and casualties without requiring changes in military tactics, special knowledge of combatant operations, or any new knowledge of enemy capabilities or weaknesses. This removes any onus on the concept of change which itself raises a sense of risk among military commanders. 


\section{STRATEGIC STRESS MANAGEMENT (SSM)}

IDT has also been described as Strategic Stress Management (SSM) in a presentation given at Carlisle Barracks about IDT by COL Brian Rees. ${ }^{10}$ The author published comments about the effects of IDT in "55 Trends Now Shaping the Future of Terrorism" (Leffler 2008) in report compiled by Forecasting International and sponsored by the Proteus Management Group, The National Intelligence University, Office of the Director of National Intelligence and the Center for Strategic Leadership at the U.S. Army War College.

\section{CURRENT IMPLEMENTATIONS OF IDT WORLD-WIDE}

Sufficient numbers of practitioners of the TM and TM-Sidhi program to achieve the Maharishi Effect are currently practicing in groups in five countries: ${ }^{11}$

- The Netherlands ( Holland )

- Trinidad and Tobago

- Bolivia

- Peru

- Colombia

In the South American countries listed, the groups consist mostly of school children. While it is noble for civilian groups to take on this responsibility, the military would be a more reliable and appropriate organization to manage IDT deployments. For instance, civilian groups must raise funds, while the military is already being paid to protect the nation from all enemies, foreign and domestic. School children take extended vacations en masse, but the military staggers leave.

Countries close to achieving sufficient numbers of IDT practitioners to achieve the Maharishi Effect include:

- India. According to Maj. Gen. Singh (Ret.), India is on the verge of achieving invincibility through civilian groups. ${ }^{12,13}$

- United States of America. Approximately 1,700 practitioners of the TM and TM-Sidhi program need to congregate twice daily to produce the Maharishi Effect for the United States. Daily tallies are kept, and this number is currently exceeded at least once per day (twice per day is the ideal to achieve the full effects of increased societal coherence). ${ }^{14}$ The group is composed mostly of American civilians, plus some experts from India. A square root of one percent calculator has been developed, to determine the approximate size of IDT groups needed any country or population size. ${ }^{15}$

\section{END NOTES}

1. (OTranscendental Meditation, TM, TM-Sidhi, Prevention Wing of the Military, are registered or common law trademarks licensed to Maharishi Vedic Education Development Corporation and used under sublicense or with permission.

2. Brown, CL (1996): Observing the assessment of research information by peer reviewers, newspaper reporters, and potential governmental and non-governmental users: International peace project in the Middle East. (Maharishi Effect.) Unpublished doctoral dissertation. Link: http://davidleffler.com/carla_linton_brown_harvard_dissertation.html

3. Travis, FT (2006): Are All Meditations the Same? Comparing the Neural Patterns of Mindfulness Meditation, Tibetan Buddhism Kargyu tradition and the Transcendental Meditation Technique. Lecture at the Science of Consciousness conference, Tucson AZ. Link: http://fredtravis.com/talk.html

4. Comparison of Techniques-Are all forms of meditation and relaxation the same? Link: http://www.truthabouttm.org/truth/Research/ComparisonofTechniques/index.cfm

5. Ultraweak Photon Emission and Meditation. Link: 
http://www.truthabouttm.org/truth/Research/NewStudies/UltraweakPhoton Emissionand Meditation/index.cfm

6. Lieutenant General José Martí Villamil (now retired), a former vice-minister of defense of Ecuador, successfully used IDT to end the war with Peru. Read an article published by India Defence Consultants for more details. Link: http://www.invinciblemilitary.org/articles/coherence.html

7. An article published by Canadian Centres for Teaching Peace entitled "Invincible Defense-A New "Secret Weapon!" written by scientists and (now retired) Navy SEAL officer describes deployment of, and underlying theory behind, the revolutionary IDT system deployed by Mozambique military. Link: http://davidleffler.com/canadiancentre.html

8. Brazilian military police pictures: Brazilian warriors learn Maharishi's Invincible Defense Technology as part of their training. Link: http://davidleffler.com/brazilpics.html

9. Brazilian military research on Invincible Defense Technology. Link: http://davidleffler.com/brazilchart.html

10. Rees, B (2006): The application of Strategic Stress Management in winning the peace. Academic Workshop sponsored by: The Proteus Management Group, USA. Hosted by the Center for Strategic Leadership United States Army War College 22-24 August 2006. Link: http://www.carlisle.army.mil/proteus/docs/Proteus-Workshop-2006 Report.pdf

11. Leffler, DR. Scoreboard of Invincible Nations. Invincible Defense Technology News, 1 January 2008. Link: http://davidleffler.com/enewsletter/20080101_IDT_News.html\#score

12. Singh, K (2008): Invincibility update from India. Invincible Defense Technology News, 1 January 2008. Link: http://davidleffler.com/enewsletter/20080101_IDT_News.html\#india

13. Invincible Defense Technology Worldwide: India. Link: http://davidleffler.com/worldwide.html\#India

14. The size of the IDT group for the United States is tallied daily. Link: http://invincibleamerica.org/tallies.html

15. Square root of one percent calculator: http://www.SquareRootOfOnePercent.org Transcription and full-sized figures link:

://istpp.org/military_science/Hagelin_military_lecture.html

\section{REFERENCES}

Alexander, CN, Cranson, RW, Boyer, RW \& Orme-Johnson, DW.(1987). Transcendental consciousness: A fourth state of consciousness beyond, sleep, dreaming, and waking. In Sleep and dreams: A sourcebook, edited by J. Gackenbach. Garland, New York, pp. 282-315.

Brown, CL. (2005). Overcoming barriers to use of promising research among elite Middle East policy groups. Journal of Social Behavior and Personality, 17(1), 489-543.

Davies, JL \& CN Alexander. (2005). Alleviating political violence through reducing collective tension: Impact Assessment analysis of the Lebanon war. Journal of Social Behavior and Personality, 17(1), 285-338.

Hagelin JS, Rainforth MV, Orme-Johnson DW, Cavanaugh KL, Alexander CN, Shatkin SF, Davies JL, Hughes AO, \& Ross, E. (1999). Effects of group practice of the Transcendental Meditation program on preventing violent crime in Washington D.C.: Results of the National Demonstration Project, June-July, 1993. Social Indicators Research, 47(2): 153-201.

Hagelin, JS. (2007). An important message for all military leaders. International Center for Invincible Defense website. Video link: http://www.invincibledefense.org/videos/2007_04_11_hagelin.html

Leffler, D, Kleinschnitz KW, Walton kg. (1999). An alternative to military violence and fear-based deterrence: Twenty years of research on the Maharishi Effect, Security and Political Risk Analysis (SAPRA). Paper is available online at: 
http://www.invinciblemilitary.org/articles/sapraalternative.html

Leffler, D. (2008). An Overlooked, Proven Solution to Terrorism. In "55 Trends Now Shaping the Future of Terrorism." Edited by Dr. Marvin J. Cetron and Owen Davies. The Proteus Trends Series, 1(2) pp. 18, 79, 176, C-13 through C 16.

Link: http://www.carlisle.army.mil/proteus/docs/55-terror.pdf

Nelson, R TM.(2006). Resonance Aggregation. Link to the 2006 IDT effects on Global Correlations in Random Data (Global Consciousness Project): http://noosphere.princeton.edu/tm.resonance.html

Nelson, R.(2005). Exploratory and Contextual Analyses. Link to the 2006 terrorist attacks effects on Global Correlations in Random Data (Global Consciousness Project) Link: http://noosphere.princeton.edu/terror.html

Orme-Johnson DW, Dillbeck MC, \& Alexander CN.(2003). Preventing terrorism and international conflict: Effects of large assemblies of participants in the Transcendental Meditation and TM-Sidhi programs. Journal of Offender Rehabilitation, 36, 283-302.

Swan, RP and Horres, EJ. (2008). Opportunity at Hand: New Roles for Carriers. Proceedings. June 2008 Vol 134/6/1,264 p. 64

Van Wijkepa, Ludtke R, \& Van Wijk, R. (2008). Differential Effects of Relaxation Techniques on Ultraweak Photon Emission. Journal of Alternative \& Complementary Medicine, 14, 241-250.

Walton KG, Cavanaugh, KL, \& Pugh, ND. (2005). Effect of group practice of the Transcendental Meditation program on biochemical indicators of stress in non meditators: A prospective time series study. Journal of Social Behavior and Personality, 17(1), 339-373. 